\title{
Neurologic sequelae of the donor arm after endoscopic versus conventional radial artery harvesting
}

\author{
Sabine Bleiziffer, MD, Ina Hettich, MD, Birgit Eisenhauer, Daniel Ruzicka, MD, Bernhard Voss, MD, \\ Robert Bauernschmitt, MD, PhD, and Ruediger Lange, MD, PhD
}

Objective: Endoscopic radial artery harvesting remarkably improves cosmetic results after coronary artery bypass surgery. The aim of this study was to investigate neurologic sequelae of the donor arm compared with those occurring after the conventional harvesting technique.

Methods: Fifty-three patients who had undergone endoscopic radial artery harvesting were followed up 1 year after the coronary artery bypass operation by means of questionnaire analysis and clinical neurologic investigation (ENDO group). Fifty-three patients who had conventional radial artery harvesting during the same time frame served as control subjects (OPEN group).

Results: Postoperative wound revision was required in 4 patients of the OPEN group ( $P=.045$ vs the ENDO group). Neurologic symptoms of the donor arm were present in 22 (OPEN group) versus 34 (ENDO group) patients $(P=.020)$ : a lesion of the superficial radial nerve was shown in 12 (OPEN group) versus 24 (ENDO) patients $(P=.014)$, and a lesion of the lateral antebrachial cutaneous nerve occurred only in the control group in 12 patients $(P<.001)$. Paraesthesia without impaired sensibility was present in 3 (OPEN group) versus 10 (ENDO group) patients $(P=.038)$. Clinical investigation revealed that temperature, pain, and touch sensation, as well as spatial discrimination, were equally impaired in symptomatic patients, whereas vibration sensation was not affected.

Conclusion: After endoscopic radial artery harvesting, impaired sensibility in the region of the superficial radial nerve and paresthesia are more frequent than after the open procedure. However, in contrast to the sequelae of the open procedure, wound revision and injury of the lateral antebrachial cutaneous nerve did not occur. Because of the excellent cosmetic results and avoidance of wound complications, we have opted to use endoscopic radial artery harvesting as the technique of choice, despite the higher incidence of sensory disturbances.

From the Clinic for Cardiovascular Surgery, German Heart Center Munich, Munich, Germany.

Received for publication Oct 8, 2007; revisions received Jan 28, 2008; accepted for publication Feb 18, 2008.

Address for reprints: Sabine Bleiziffer, MD, Clinic for Cardiovascular Surgery, German Heart Center Munich, Lazarettstr. 36, 80636 Munich, Germany (E-mail: bleiziffer@dhm.mhn.de).

J Thorac Cardiovasc Surg 2008;136:681-7 $0022-5223 / \$ 34.00$

Copyright $(2008$ by The American Association for Thoracic Surgery

doi:10.1016/j.jtcvs.2008.02.067
$\mathrm{B}$ ecause of patency rates superior to those of the sapheneous vein, ${ }^{1}$ radial artery (RA) grafts have been widely used for coronary artery bypass grafting after their reintroduction by Acar and colleagues in the 1990s. ${ }^{2}$ Because endoscopic vein harvesting has proved to be advantageous over the conventional harvesting technique ${ }^{3-6}$ attempts have been made to develop techniques for endoscopic RA harvesting since $1998 .^{7-10}$

Because of the anatomic tight relations of the RA to the accompanying nerves, there are concerns about neurologic symptoms after nerve injury at the forearm when dissecting the RA. Two afferent nerves are mainly susceptible for damage during RA harvesting: the lateral antebrachial cutaneous nerve (LACN), which has a superfascial position and might be injured by the forearm skin incision and subcutaneous dissection, and the superficial radial nerve (SRN), which has a tight relation to the RA at the distal forearm. The sensitive areas supplied by those nerves are shown in Figure 1.

Because the LACN is not reached by the endoscopic harvesting, clinicians suggested that neurologic sequelae might be reduced by using the endoscopic 


\section{Abbreviations and Acronyms}

$\mathrm{LACN}=$ lateral antebrachial cutaneous nerve

$\mathrm{RA}=$ radial artery

$\mathrm{SRN}=$ superficial radial nerve

technique. ${ }^{11}$ The aim of the present study was to assess the incidence and character of neurologic sequelae of the forearm, comparing endoscopic and conventional RA harvesting.

\section{Materials and Methods}

At our institution, the RA is chosen as a bypass graft in patients aged less than 70 years and in the absence of contraindications, such as carpal tunnel syndrome, M. Dupuytren, severe arterial obstructive disease, end-stage renal insufficiency, a pathologic Allen test result, or Doppler examination revealing small RA diameter or visible calcification. Of 1403 patients who underwent coronary artery bypass grafting between March 2004 and July 2005, 397 received an RA graft. Of these, 71 patients underwent endoscopic RA harvesting (ENDO group). Fifty-three patients could be recruited for questionnaire analysis: 10 patients live abroad, and 8 patients refused the follow-up. As a control group, we randomly selected 53 patients undergoing conventional RA harvesting who were operated on during the same time period (OPEN group). The RA was taken from the nondominant arm, which was the left arm in all study patients. Patient characteristics are summarized in Table 1.

\section{RA Harvesting}

The nondominant arm was chosen for RA harvesting. Preoperative Allen tests and Doppler examinations were routinely performed to confirm adequate ulnar blood flow.

Endoscopic RA harvesting was performed through a 3-cm skin incision. This technique is performed with an endoscope inserted

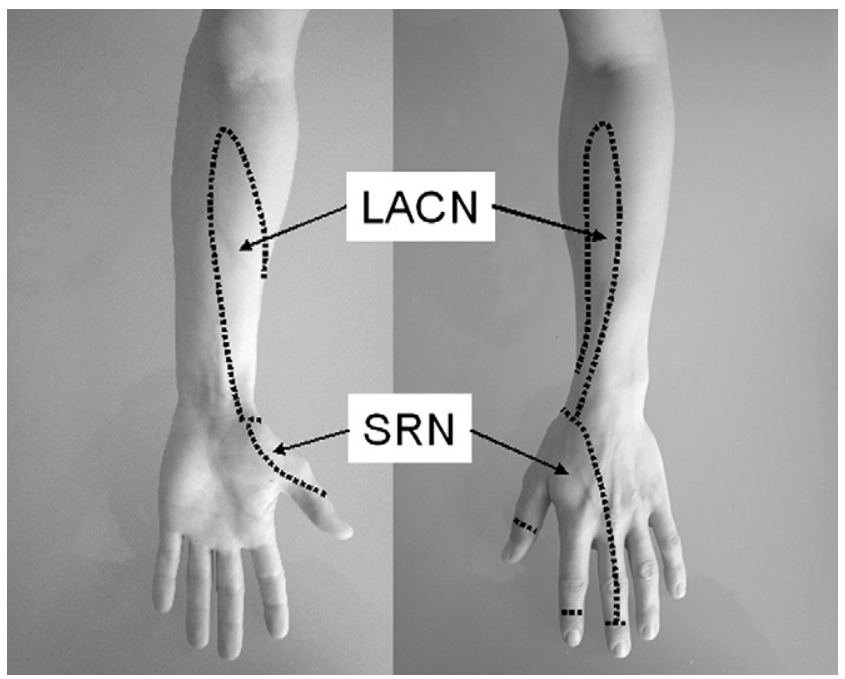

Figure 1. Areas of the forearm supplied by the superficial radial nerve (SRN) and the lateral antebrachial cutaneous nerve (LACN) viewed from the palmar (left) and dorsal (right) sides.
TABLE 1. Patient characteristics

\begin{tabular}{lccc}
\hline & ENDO group & OPEN group & P value \\
\hline Mean age at operation (y) & $60.8 \pm 6.9$ & $60.6 \pm 9.0$ & .885 \\
Sex (F/M) & $7 / 46$ & $7 / 46$ & 1.0 \\
Diabetes mellitus & $8 / 53(15 \%)$ & $6 / 53(11 \%)$ & .566 \\
Peripheral vessel disease & $6 / 53(11 \%)$ & $8 / 53(15 \%)$ & .566 \\
Smoking history & $16 / 53(39 \%)$ & $19 / 53(36 \%)$ & .536 \\
Systemic hypertension & $45 / 53(85 \%)$ & $49 / 53(92 \%)$ & .220
\end{tabular}

OPEN, Conventional radial artery harvesting $(\mathrm{n}=53)$; ENDO, endoscopic radial artery harvesting $(n=53)$.

into a retractor and a harmonic scalpel for the dissection of the artery. Proximal transection of the artery is carried out with a pretied endoloop. A detailed description of the technique was published elsewhere. ${ }^{12}$ In our first 21 patients, a counterincision was made for proximal ligation of the artery.

Conventional RA harvesting was carried out by using electrocautery or the harmonic scalpel. Interrupted incisions (instead of a single long incision) were made in 15 of 53 patients to improve the cosmetic result.

Antispasmodic prophylaxis was carried out in all patients by means of intravenous application of 6 to $12 \mu \mathrm{g}$ of diltiazem per kilogram per minute, starting during extracorporeal circulation and continuing for 24 hours after the operation. We also recommended the administration of amlodipine as an antispasmodic agent in an oral dose of $5 \mathrm{mg} / \mathrm{d}$ for 3 months after the operation.

\section{Questionnaire Analysis}

As a first step in our investigation, we evaluated clinical status and the incidence and type of neurologic impairment of the donor arm after endoscopic $(n=53)$ versus conventional $(n=53)$ RA harvesting by using a questionnaire follow-up $15.1 \pm 5.3$ months postoperatively. We evaluated the existence of muscle weakness, paresthesia, and impaired sensibility and the area of impaired sensibility at the harvesting forearm. In case of insufficient declaration by the patient in the questionnaire, we clarified the type of neurologic impairment by means of an additional telephone interview.

\section{Neurologic Investigation}

Forty-seven patients of the ENDO group could be recruited for clinical neurologic investigation of the forearms ( 6 patients refused the neurologic investigation) to evaluate specific patterns of sensory disturbances. Evaluation of muscle strength was carried out by means of manual examination. The tests are described in Table 2. Differences between the left and right upper limbs were recorded.

Four monosynaptic stretch reflexes of the upper limb were tested (Table 3). Differences between the left and right limbs were recorded.

The evaluation of sensory disturbances was performed by testing temperature, pain, and touch sensation each at 10 defined spots on both forearms with the patients' eyes closed. Thus a maximum score of 10 could be achieved for each sensation quality. Additionally, we calculated the difference of the score (maximum of 10) of each forearm (score of the right forearm minus score of the left forearm). Consequently, a positive score difference indicates a sensory deficit of the left forearm, and a negative difference indicates a sensory deficit of the right forearm. Spatial discrimination was tested at the radial 
TABLE 2. Evaluation of muscle strength (ENDO group)

\begin{tabular}{|c|c|c|c|c|}
\hline Test & Explanation & Main muscles tested & Result & $P$ value (Wilcoxon test) \\
\hline Squeezing hands & $\begin{array}{l}\text { Patient squeezes the } \\
\text { crossed hands of the } \\
\text { investigator }\end{array}$ & $\begin{array}{l}\text { Small hand muscles, flexors } \\
\text { of the forearm }\end{array}$ & $\begin{array}{l}\text { No differences between left } \\
\text { and right limb }\end{array}$ & 1 \\
\hline Straddle fingers & $\begin{array}{l}\text { Patient straddles digits } \\
\text { II through V against } \\
\text { force of the investigator }\end{array}$ & $\begin{array}{l}\text { M. abductor digiti minimi, } \\
\text { Mm. interossei dorsales }\end{array}$ & $\begin{array}{l}\text { Impairment of the left limb in } \\
2 / 47 \text { patients }\end{array}$ & .157 \\
\hline Clamp fingers & $\begin{array}{l}\text { Opposition of the } \\
\text { thumb toward digit } V \\
\text { against the force of the } \\
\text { investigator }\end{array}$ & M. opponens pollicis & $\begin{array}{l}\text { Impairment of the left limb in } \\
1 / 47 \text { patients }\end{array}$ & .317 \\
\hline Flex forearm & $\begin{array}{l}\text { Patient bends the } \\
\text { forearm against } \\
\text { the force of the } \\
\text { investigator }\end{array}$ & $\begin{array}{l}\text { M. biceps brachii, } \\
\text { M. brachioradialis }\end{array}$ & $\begin{array}{l}\text { No differences between left } \\
\text { and right limbs }\end{array}$ & 1 \\
\hline Stretch forearm & $\begin{array}{l}\text { Patient stretches the } \\
\text { forearm against } \\
\text { the force of the } \\
\text { investigator }\end{array}$ & M. triceps brachii & $\begin{array}{l}\text { No differences between left } \\
\text { and right limb }\end{array}$ & 1 \\
\hline
\end{tabular}

ENDO, Endoscopic radial artery harvesting $(\mathrm{n}=53)$.

side of the thenar eminence, which is the area most frequently affected by sensory disturbances. The minimal distance (in millimeters) that was recognized as 2 spots was recorded, and the difference between the right and left forearms was calculated (minimal distance of right forearm minus minimal distance of left forearm). Vibration sensation was tested with a $128-\mathrm{Hz}$ tuning fork with a 1- to 8-point scale at both radial styloid processes. Again, the difference between the right and left forearms was calculated for data analysis.

\section{Statistical Analysis}

Data are presented as means \pm standard deviation or as simple percentages. Differences between groups were tested by using the Student's $t$ test or the $\chi^{2}$ test, as appropriate. Differences of muscle strength and stretch reflexes between the left and right limb were tested by using the Wilcoxon test for dependent variables. Differences of sensory disturbances between the left and right limbs were tested by using the Student's $t$ test for dependent continuous variables.

\section{Results}

Questionnaire analysis demonstrated that 19 of 53 (ENDO group) versus 31 of 53 (OPEN group) patients had no dis- comfort at the harvesting site $(P=.020)$. A higher proportion of patients in the ENDO group exhibited paresthesia without sensation impairment (10/53 vs 3/53 [OPEN group], $P=$ .038). Numbness in the area supplied by the SRN was reported in 24/53 (ENDO group) versus 12/53 (OPEN group) patients $(P=.014)$, whereas sensation impairment in the area supplied by the LACN was only present in the OPEN group in 12 of 53 patients $(P<.001)$.

The patterns of sensory disturbance are summarized in Figure 2.

None of the patients reported muscular weakness of the thumb or the forearm after RA harvesting. Two patients (1 in the ENDO group and 1 in the OPEN group) reported numbness in the area supplied by the ulnar nerve. In 4 of 53 patients of the OPEN group, postoperative wound revision was required ( $\mathrm{n}=1$ infection, $\mathrm{n}=3$ suture granuloma), whereas in the ENDO group no reoperations were performed on the harvesting site $(P=.045)$.

\section{Neurologic Investigation (ENDO Group)}

Forty-seven patients were recruited for detailed neurologic investigation. In 3 patients weakness of the thumb $(n=1)$

TABLE 3. Monosynaptic stretch reflexes (ENDO group)

\begin{tabular}{lllc}
\hline Monosynaptic stretch reflex & \multicolumn{1}{c}{ Nerves involved } & Result & $P$ value (Wilcoxon test) \\
\hline Biceps brachii reflex & C5/C6, musculocutaneous nerve & No differences between left and right limbs & 1 \\
Triceps brachii reflex & $\mathrm{C} 6 / \mathrm{C} 7$, radial nerve & No differences between left and right limbs & 1 \\
Brachioradial reflex & $\mathrm{C} 5 / \mathrm{C} 6$, radial nerve & No differences between left and right limbs & 1 \\
Tromner reflex & $\mathrm{C} 7-T h 1$, median and ulnar nerve & No differences between left and right limbs & 1 \\
\hline
\end{tabular}

ENDO, Endoscopic radial artery harvesting $(\mathrm{n}=53)$. 


\begin{tabular}{|c|c|c|c|c|c|c|}
\hline no symptoms & $\begin{array}{c}\text { paraesthesia } \\
\text { only }\end{array}$ & SRN (1) & SRN (2) & LACN & LACN+SRN \\
OPEN & 31 & 3 & 2 & $\begin{array}{c}5 \\
(3 \text { without } \\
\text { Earaesthesia) }\end{array}$ & $\begin{array}{c}(4 \text { without } \\
\text { paraesthesia) }\end{array}$ & $\begin{array}{c}(1 \text { without } \\
\text { paraesthesia) }\end{array}$ \\
19 & 10 & $\begin{array}{c}19 \\
\text { (15 without } \\
\text { paraesthesia) }\end{array}$ & $\begin{array}{c}\text { (1 without } \\
\text { paraesthesia) }\end{array}$ & - & - \\
\hline
\end{tabular}

Figure 2. Detailed illustration of the patterns of sensory impairment seen in both groups. OPEN, Conventional radial artery harvesting ( $\mathrm{n}=53$ ); ENDO, endoscopic radial artery harvesting $(n=53)$; $S R N$, superficial radial nerve; $L A C N$, lateral antebrachial cutaneous nerve. or the fingers $(\mathrm{n}=2)$ was detected at the harvesting site (Table 2). The monosynaptic stretch reflexes were not different between the left and right limbs (Table 3). The evaluation of sensory disturbances revealed a significant impairment of the mean scores for touch, temperature, and pain sensation and a significant impairment of the mean spatial discrimination at the donor arm in patients reporting sensory loss (regardless of paresthesia), whereas vibration sensation was not affected (Table 4).

The histograms in Figure 3 demonstrate the distribution of score differences between the right and left forearms. Patients who reported no sensory loss show a curve for standard distribution, with the peak at a score difference of zero (ie, no difference between right and left forearm), whereas patients with sensory loss show a shift of the peak of the curve toward the right side of the diagram, indicating a left forearm impairment of pain, temperature, and touch sensation and spatial discrimination. The curves for vibration sensation are similar in symptomatic and asymptomatic patients.

\section{Discussion}

The present study aims to evaluate neurologic sequelae of the donor arm after endoscopic RA harvesting for coronary artery bypass surgery compared with that after the conventional harvesting technique. There are several aspects of minimally invasive RA harvesting that deserve appreciation when compared with open harvesting.

First, a reduced skin incision is considered to significantly minimize wound complications, as shown in a recent comparative study. ${ }^{13}$ Similarly, in our cohort no reoperations were performed at the harvesting site in the ENDO group, whereas in 4 patients of the OPEN group, wound revision was required $(P=.045)$.

Second, graft quality is required to be comparable with that of the open technique to justify the endoscopic harvesting. Recently, we demonstrated equal 1-year patency rates for both techniques by means of 64-slice computed tomography. ${ }^{14}$

Third, for the majority of the patients, the cosmetic aspect of the minimally invasive techniques might be an important argument for the acceptance of the RA as a conduit for coronary artery bypass grafting, thus avoiding a long scar across the forearm.

Finally, neurologic deficits have been reported as significant side effects for both the conventional and endoscopic harvesting techniques.

Reports on the incidence of neurologic impairment after RA harvesting range from $0 \%$ to $86 \%$, regardless of the harvesting technique (Table 5). ${ }^{11,15-29}$ This broad range can only

TABLE 4. Evaluation of sensory disturbances (ENDO group)

\begin{tabular}{|c|c|c|c|c|c|c|}
\hline & \multicolumn{2}{|c|}{ Patients reporting sensory loss $(n=20)$} & \multicolumn{2}{|c|}{ Patients reporting no sensory loss $(n=27$ ) } & \multicolumn{2}{|c|}{ All patients $(n=47)$} \\
\hline & Left forearm & Right forearm & Left forearm & Right forearm & Left forearm & Right forearm \\
\hline Temperature (score of 1-10) & $6.5 \pm 2.4$ & $9.4 \pm 1.0^{*}$ & $8.9 \pm 1.4$ & $9.1 \pm 1.4$ & $7.9 \pm 2.2$ & $9.2 \pm 1.3^{*}$ \\
\hline Touch (score of 1-10) & $6.6 \pm 2.0$ & $9.9 \pm 0.4^{*}$ & $9.7 \pm 0.7$ & $9.7 \pm 1.0$ & $8.4 \pm 2.1$ & $9.8 \pm 0.8^{*}$ \\
\hline Pain (score of 1-10) & $7.7 \pm 2.2$ & $10.0 \pm 0.2^{*}$ & $9.6 \pm 1.6$ & $9.6 \pm 1.5$ & $8.8 \pm 2.0$ & $9.7 \pm 1.1^{*}$ \\
\hline Spatial discrimination (mm) & $41.5 \pm 24.9$ & $18.5 \pm 6.1^{*}$ & $27.2 \pm 27.7$ & $20.2 \pm 10.3$ & $33.3 \pm 27.3$ & $19.5 \pm 8.7^{*}$ \\
\hline Vibration (scale of 1-8) & $7.2 \pm 0.8$ & $7.4 \pm 0.7$ & $7.3 \pm 0.7$ & $7.4 \pm 0.6$ & $7.3 \pm 0.7$ & $7.4 \pm 0.6$ \\
\hline
\end{tabular}

ENDO, Endoscopic radial artery harvesting $\left(\mathrm{n}=53\right.$ ). ${ }^{*} P \leq .002$, left versus right forearm. 

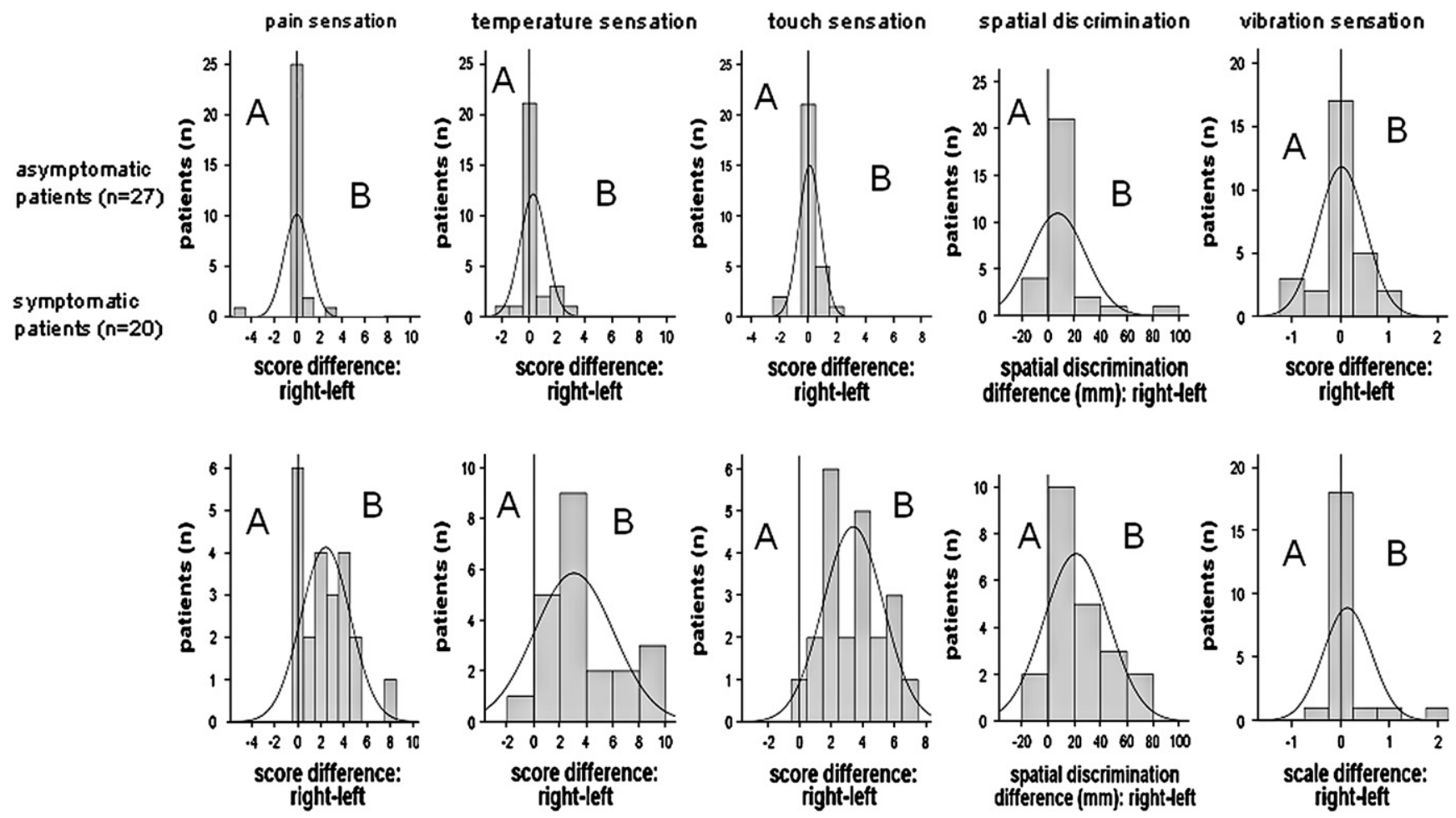

Figure 3. Histograms of the score differences (right forearm minus left forearm) for pain, temperature, touch, and vibration sensation and spatial discrimination. $A$, Negative score, respectively. better sensation of the left forearm (donor arm); B, positive score, respectively. better sensation of the right forearm. Noticeably, in patients with sensory loss, the qualities of pain, temperature, and touch sensation and spatial discrimination are equally impaired at the donor arm (right-sided shift of the peak of the distribution curve), whereas vibration sensation is not affected.

be explained by different focuses of the articles and different methods of evaluation of the neurologic symptoms.

A certain proportion of those studies mainly focus on the description of the RA harvesting technique or on the safety of RA grafting, ${ }^{11,15,19,20,23,24,27}$ whereas the data on neurologic sequelae remain insufficient. The authors of studies focusing on arm complications after RA harvesting base the evaluation of neurologic symptoms either only on subjective patients' reports (telephone interview, questionnaire, or subjective grading on a scale) $)^{16,17,21,25,29}$ or on electromyographic or electronystagmographic analysis ${ }^{26,28}$ or neurologic examination. $^{18,22}$ In the present study we combined a questionnaire analysis with a neurologic examination. Patients' assessments of sensory disturbances could be confirmed by the objective investigation in all cases, whereas thumb or finger weakness was detected in 3 patients who did not complain about motor deficits. Therefore we state that subjective evaluation of neurologic symptoms by the patients is feasible to detect sensory, but not motor, deficits.

There are several explanations for the mechanisms of neurologic impairment: direct nerve trauma during harvesting might explain sensory deficits of the areas supplied by the
LACN and SRN. It could be speculated that local edema or hematoma also might cause damage of the forearm nerves. Additionally, parts of the symptoms might be attributed to ischemic neuropathy if ulnar collateral blood supply becomes insufficient to nerves that are devascularized by means of RA harvesting. This mechanism might be of clinical relevance in patients with risk factors associated with vascular disease, such as diabetes, smoking, and peripheral vessel disease. ${ }^{16}$ However, Knobloch and associates ${ }^{30}$ demonstrated only minor insignificant impairment of microcirculation in the donor arm 2 years after surgical intervention. Therefore neurologic symptoms might not exclusively be attributed to vascular changes of the donor site. Dogan and colleagues ${ }^{28}$ state that mechanical factors, such as chest retraction and arm abduction, as well as left internal thoracic artery preparation, also can cause neurologic impairment.

In accordance with other studies, we found a variety of sensory deficit patterns (Figure 2). As expected, the LACN was avoided by means of endoscopic RA harvesting. This observation has previously been described by other authors. ${ }^{11,31}$ Interestingly, in patients with symptoms concerning the SRN, sensory loss did not affect the complete area 
TABLE 5. Incidence of neurologic sequelae after RA harvesting in the literature

\begin{tabular}{|c|c|c|c|c|c|c|c|}
\hline Author & Year & No. of patients & Harvest & Any neurologic symptoms & Sensory disturbance & Thumb weakness & Follow-up time \\
\hline Tatoulis and coworkers $^{15}$ & 1998 & 192 & OPEN & $33 \%$ & $10 \%$ & $0.5 \%$ & $5.5 \mathrm{mo}$ \\
\hline Denton and coworkers ${ }^{16}$ & 2001 & 560 & OPEN & $30 \%$ & $18 \%$ & $5.5 \%$ & $15 \mathrm{mo}$ \\
\hline Saeed and coworkers ${ }^{17}$ & 2001 & 127 & OPEN & $70 \%$ & $68 \%$ & $3 \%$ & $8 \mathrm{mo}$ \\
\hline Greene and Malias $^{18}$ & 2001 & 338 & OPEN & & $11 \%$ & & At discharge \\
\hline Connolly and coworkers ${ }^{19}$ & 2002 & 300 & ENDO & & $9 \%$ & & $1 \mathrm{mo}$ \\
\hline Newman and Lammle ${ }^{20}$ & 2003 & 100 & ENDO & & $14 \%$ & & At discharge \\
\hline Moon and coworkers ${ }^{21}$ & 2004 & 786 & OPEN & $11 \%$ & $11 \%$ & $3 \%$ & $12 \mathrm{mo}$ \\
\hline Siminelakis and coworkers 22 & 2004 & 54 & OPEN & $34 \%$ & $34 \%$ & $7 \%$ & $16 \mathrm{mo}$ \\
\hline Casselman and coworkers ${ }^{11}$ & 2004 & 54 & ENDO & & $28 \%$ & & $6 \mathrm{wk}$ \\
\hline Miles and coworkers ${ }^{23}$ & 2004 & 50 & ENDO & & $4 \%$ & & At discharge \\
\hline Shapira and coworkers ${ }^{24}$ & 2004 & 75 & ENDO & $86 \%$ & & & At discharge \\
\hline Knobloch and coworkers ${ }^{25}$ & 2005 & 211 & OPEN & $12 \%$ & $12 \%$ & $3 \%$ & $26 \mathrm{mo}$ \\
\hline Ikizler and coworkers ${ }^{26}$ & 2005 & 50 & OPEN & $28 \%$ & $32 \%$ & $6 \%$ & 3 wk \\
\hline Yoshizaki and coworkers ${ }^{27}$ & 2005 & 25 & ENDO & & $21 \%$ & & $8 \mathrm{mo}$ \\
\hline \multirow[t]{2}{*}{ Shapira and coworkers ${ }^{29}$} & 2006 & 108 & ENDO & & $39 \%$ & & $12 \mathrm{wk}$ \\
\hline & & 120 & OPEN & & $38 \%$ & & $46 \mathrm{wk}$ \\
\hline Dogan and coworkers ${ }^{28}$ & 2006 & 20 & OPEN & $0 \%$ & $0 \%$ & $0 \%$ & $3 \mathrm{mo}$ \\
\hline
\end{tabular}

supplied by the SRN (as shown in Figure 1) because sensation of digit III was not impaired in any patient, indicating only partial lesion of the SRN. However, SRN injury was significantly more frequent in the ENDO group. This phenomenon has not been described previously. Shapira and coworkers $^{29}$ report an equal incidence of sensory deficits in a study comparing outcome after endoscopic versus conventional RA harvesting. However, in their conventional harvesting group, patients exhibited LACN and SRN impairment, whereas in the endoscopic harvesting group only the SRN was affected, implicating that symptoms caused by SRN injury are more frequent after the endoscopic harvesting. As a possible explanation, we speculate that in the limited working channel during endoscopic harvesting, the heat from the harmonic scalpel might raise the tissue temperature dramatically and cause thermal lesion of the nerve, whereas during conventional harvesting, the heat might dissipate through the open wound. There is evidence that the type of energy used for RA dissection might interfere with postoperative sensory deficits because Onorati and associates $^{32}$ found significantly lower incidences of postoperative hand sensory deficits in patients after RA harvesting when clips and scissors were used as opposed to the harmonic scalpel or electrocautery.

In addition to sensory loss, we also evaluated the incidence of paresthesia after RA harvesting, which is defined as "prickle" or hypersensitivity. There was a significantly higher proportion of patients in the ENDO group complaining about hand paresthesia without sensory loss, which might also be attributed to partial thermal SRN damage. Few studies distinguish between paresthesia and sensory loss. Royse and colleagues $^{33}$ report an incidence of $20 \%$ paresthesia after conventional RA harvesting, which is higher than in our OPEN cohort but comparable with that seen in our ENDO group.

Neurologic examination revealed no impairment of the monosynaptic stretch reflexes in our study but minor impairment of finger or thumb muscle strength in 3 patients, which might be caused by thermal or ischemic lesions of branches of the median nerve. Proprioception, represented by the assessment of vibration sensation, is not impaired after RA harvesting. In patients reporting numbness, the sensation qualities of pain, temperature, touch, and spatial discrimination were equally impaired, as shown in the histograms in Figure 3.

In 2 patients ( 1 in the ENDO group and 1 in the OPEN group) a lesion of the ulnar nerve was detected, which might be attributed to compression during abduction of the donor arm during the harvesting procedure. Care must be taken to cushion the sulcus ulnaris when the forearm is mounted on the holder.

\section{Conclusions}

In summary, we demonstrated that the incidence of sensory disturbances is more frequent after endoscopic versus conventional RA harvesting, which is attributed to paresthesia and SRN lesions. The LACN is avoided with the endoscopic harvesting technique, and postoperative wound complications did not occur. Despite the higher incidence of sensory disturbances after endoscopic RA harvesting, we have opted to use it as the technique of choice because of the excellent cosmetic results and avoidance of wound complications. However, for the individual patient, it might be better to have a scar than loss of sensation in important areas of the 
hand, depending on profession or lifestyle. The persistence of sensory symptoms is of relevance when obtaining preoperative informed consent independent of the chosen RA harvesting technique. Future investigations of neurologic sequelae of RA harvesting should include neurologic examination because subjective patients' reports might obscure motor deficits. Future studies should investigate the effect of different energy sources (harmonic scalpel vs electrocautery) on the incidence of neurologic symptoms after endoscopic RA harvesting.

\section{Limitations}

The present study represents a 1-year follow-up after RA harvesting. The groups were not randomized. The study was based on questionnaire evaluation, which might pose a bias because patients could have deficits of some sort and not be aware of them or have compensated for them. Furthermore, this is a retrospective study that might have introduced biases. A clinical neurologic investigation was only performed in the group of patients who underwent endoscopic RA harvesting. The fact that 2 techniques were performed in the control group (one long incision or interrupted incisions) might have influenced the incidence of LACN lesions. We did not investigate a potential regression of sensory symptoms over time.

\section{References}

1. Desai ND, Cohen EA, Naylor CD, Fremes SE. A randomized comparison of radial-artery and saphenous-vein coronary bypass grafts. $N$ Engl $J$ Med. 2004;351:2302-9.

2. Acar C, Jebara VA, Portoghese M, Beyssen B, Pagny JY, Grare P, et al. Revival of the radial artery for coronary artery bypass grafting. Ann Thorac Surg. 1992;54:652-60.

3. Illig KA, Rhodes JM, Sternbach Y, Shortell CK, Davies MG, Green RM. Reduction in wound morbidity rates following endoscopic saphenous vein harvest. Ann Vasc Surg. 2001;15:104-9.

4. Allen KB, Heimansohn DA, Robison RJ, Schier JJ, Griffith GL, Fitzgerald EB. Influence of endoscopic versus traditional saphenectomy on event-free survival: five-year follow-up of a prospective randomized trial. Heart Surg Forum. 2003;6:E143-5.

5. Bitondo JM, Daggett WM, Torchiana DF, Akins CW, Hilgenberg AD, Vlahakes GJ, et al. Endoscopic versus open saphenous vein harvest: a comparison of postoperative wound complications. Ann Thorac Surg. 2002;73:523-8.

6. Schurr UP, Lachat ML, Reuthebuch O, Kadner A, Mader M, Seiffert B, et al. Endoscopic saphenous vein harvesting for $\mathrm{CABG}$ - a randomized, prospective trial. Thorac Cardiovasc Surg. 2002;50:160-3.

7. Casula RP, Kumar P, Ashrafian H, Athanasiou T. Evolving techniques for endoscopic radial artery harvesting. Cardiovasc Surg. 2003;11: 425-7.

8. Genovesi MH, Torrillo L, Fonger J, Patel N, McCabe JC, Subramanian VA. Endoscopic radial artery harvest: a new approach. Heart Surg Forum. 2001;4:223-5.

9. Galajda Z, Peterffy A. Minimally invasive harvesting of the radial artery as a coronary artery bypass graft. Ann Thorac Surg. 2001;72:291-3.

10. Uchida A, Hochberg J, Terada Y, Fukuda I, Cruzzavala J, GonzalezCruz R, et al. Endoscopic harvesting of radial artery graft for coronary artery bypass. Ann Plast Surg. 1998;41:459-63.

11. Casselman FP, La Meir M, Cammu G, Wellens F, De Geest R, Degrieck I, et al. Initial experience with an endoscopic radial artery harvesting technique. J Thorac Cardiovasc Surg. 2004;128:463-6.
12. Bleiziffer S, Libera $P$, Lange R. Endoscopic radial artery harvesting through a single incision. Thorac Cardiovasc Surg. 2006;54:208-9.

13. Patel AN, Henry AC, Hunnicutt C, Cockerham CA, Willey B, Urschel HC Jr. Endoscopic radial artery harvesting is better than the open technique. Ann Thorac Surg. 2004;78:149-53.

14. Bleiziffer S, Hettich I, Eisenhauer B, Ruzicka D, Wottke M, Hausleiter J, et al. Patency rates of endoscopically harvested radial arteries one year after coronary artery bypass grafting. I Thorac Cardiovasc Surg. 2007;134:649-56.

15. Tatoulis J, Buxton BF, Fuller JA. Bilateral radial artery grafts in coronary reconstruction: technique and early results in 261 patients. Ann Thorac Surg. 1998;66:714-20.

16. Denton TA, Trento L, Cohen M, Kass RM, Blanche C, Raissi S, et al. Radial artery harvesting for coronary bypass operations: neurologic complications and their potential mechanisms. $J$ Thorac Cardiovasc Surg. 2001;121:951-6.

17. Saeed I, Anyanwu AC, Yacoub MH, Amrani M. Subjective patient outcomes following coronary artery bypass using the radial artery: results of a cross-sectional survey of harvest site complications and quality of life. Eur J Cardiothorac Surg. 2001;20:1142-6.

18. Greene MA, Malias MA. Arm complications after radial artery procurement for coronary bypass operation. Ann Thorac Surg. 2001;72:126-8.

19. Connolly MW, Torrillo LD, Stauder MJ, Patel NU, McCabe JC, Loulmet DF, et al. Endoscopic radial artery harvesting: results of first 300 patients. Ann Thorac Surg. 2002;74:502-6.

20. Newman RV, Lammle WG. Radial artery harvest using endoscopic techniques. Heart Surg Forum. 2003;6:E194-5.

21. Moon MR, Barner HB, Bailey MS, Lawton JS, Moazami N, Pasque MK, et al. Long-term neurologic hand complications after radial artery harvesting using conventional cold and harmonic scalpel techniques. Ann Thorac Surg. 2004;78:535-8.

22. Siminelakis S, Karfis E, Anagnostopoulos C, Toumpoulis I, Katsaraki A, Drossos G. Harvesting radial artery and neurologic complications. J Card Surg. 2004;19:505-10.

23. Miles RH, Kollpainter RE, Riveron FA, Johnkoski JA. The pneumatic tourniquet technique for endoscopic radial artery harvest. J Card Surg. 2004; 19:495-8

24. Shapira OM, Eskenazi B, Murphy R, Anter E, Bao Y, Lazar HL, et al. Endoscopic radial artery harvest for coronary artery bypass grafting: initial clinical experience. Heart Surg Forum. 2004;7:E411-5.

25. Knobloch K, Lichtenberg A, Tomaszek S, Hagl C, Khaladj N, Klima U, et al. Long-term physical activity and neurologic function after harvesting of the radial artery as T-graft or free graft in coronary revascularization. Ann Thorac Surg. 2005;80:918-21.

26. Ikizler M, Ozkan S, Dernek S, Ozdemir C, Erdinc OO, Sevin B, et al. Does radial artery harvesting for coronary revascularization cause neurological injury in the forearm and hand? Eur J Cardiothorac Surg. 2005;28:420-4.

27. Yoshizaki T, Arai H, Igari T, Tabuchi N, Tanaka H, Sunamori M. Endoscopic radial artery harvesting: our initial experience and results of the first 25 patients. Ann Thorac Cardiovasc Surg. 2005;11:391-6.

28. Dogan OV, Duzgun C, Ozeren M, Alanoglu E, Dogan S, Simsek E, et al. Subclinical injury to forearm nerves during radial harvesting: electrophysiologic study. J Card Surg. 2006;21:151-4.

29. Shapira OM, Eskenazi BR, Hunter CT, Anter E, Bao Y, Murphy R, et al. Endoscopic versus conventional radial artery harvest-is smaller better? J Card Surg. 2006;21:329-35.

30. Knobloch K, Tomaszek S, Lichtenberg A, Karck M, Haverich A. Longterm palmar microcirculation after radial artery harvesting: an observational study. Ann Thorac Surg. 2006;81:1700-7.

31. Shapira OM, Eskenazi BR, Anter E, Joseph L, Christensen TG, Hunter CT, et al. Endoscopic versus conventional radial artery harvest for coronary artery bypass grafting: functional and histologic assessment of the conduit. $J$ Thorac Cardiovasc Surg. 2006;131:388-94.

32. Onorati F, De Feo M, Cristodoro L, Esposito A, Perrotti A, Mastroroberto $\mathrm{P}$, et al. Can harvesting techniques modify postoperative results of the radial artery conduit? Ital Heart J. 2005;6:911-6.

33. Royse AG, Royse CF, Shah P, Williams A, Kaushik S, Tatoulis J. Radial artery harvest technique, use and functional outcome. Eur $J$ Cardiothorac Surg. 1999;15:186-93. 